\title{
Timing for successful surgical management of heart block after placement of an Amplatzer occlusion device for secundum atrial septal defect repair
}

\author{
Umang Gupta, MBBS, DCH, Shadda J. Al-anani, MD, and Anastasios C. Polimenakos, MD, Chicago, Ill
}

Atrioventricular (AV) blocks are rare complication that can occur after device closure of an atrial septal defect (ASD). ${ }^{1,2}$ Review of the manufacturer and user facility device experience (MAUDE) database by Delaney, Li, and Rhodes $^{3}$ indicated one reported complication of a second-degree AV block after insertion of an ASD occlusion device. Development of complete AV block is even less common. ${ }^{4}$ Most of these cases resolve either spontaneously or with medical management in a few days. We report a case in which complete AV block did not resolve spontaneously

From Rush University Medical Center, Pediatric Cardiology, Chicago, Ill.

Disclosures: Authors have nothing to disclose with regard to commercial support.

Received for publication June 29, 2010; accepted for publication July 31, 2010; available ahead of print Sept 20, 2010.

Address for reprints: Umang Gupta, MBBS, DCH, Rush University Medical Center, Pediatric Cardiology, 1653 West Congress Parkway, Suite 761 Jones, Chicago, IL 60612 (E-mail: umang_gupta@rush.edu)

J Thorac Cardiovasc Surg 2011;141:1319-21

$0022-5223 / \$ 36.00$

Copyright (c) 2011 by The American Association for Thoracic Surgery doi:10.1016/j.jtcvs.2010.07.080
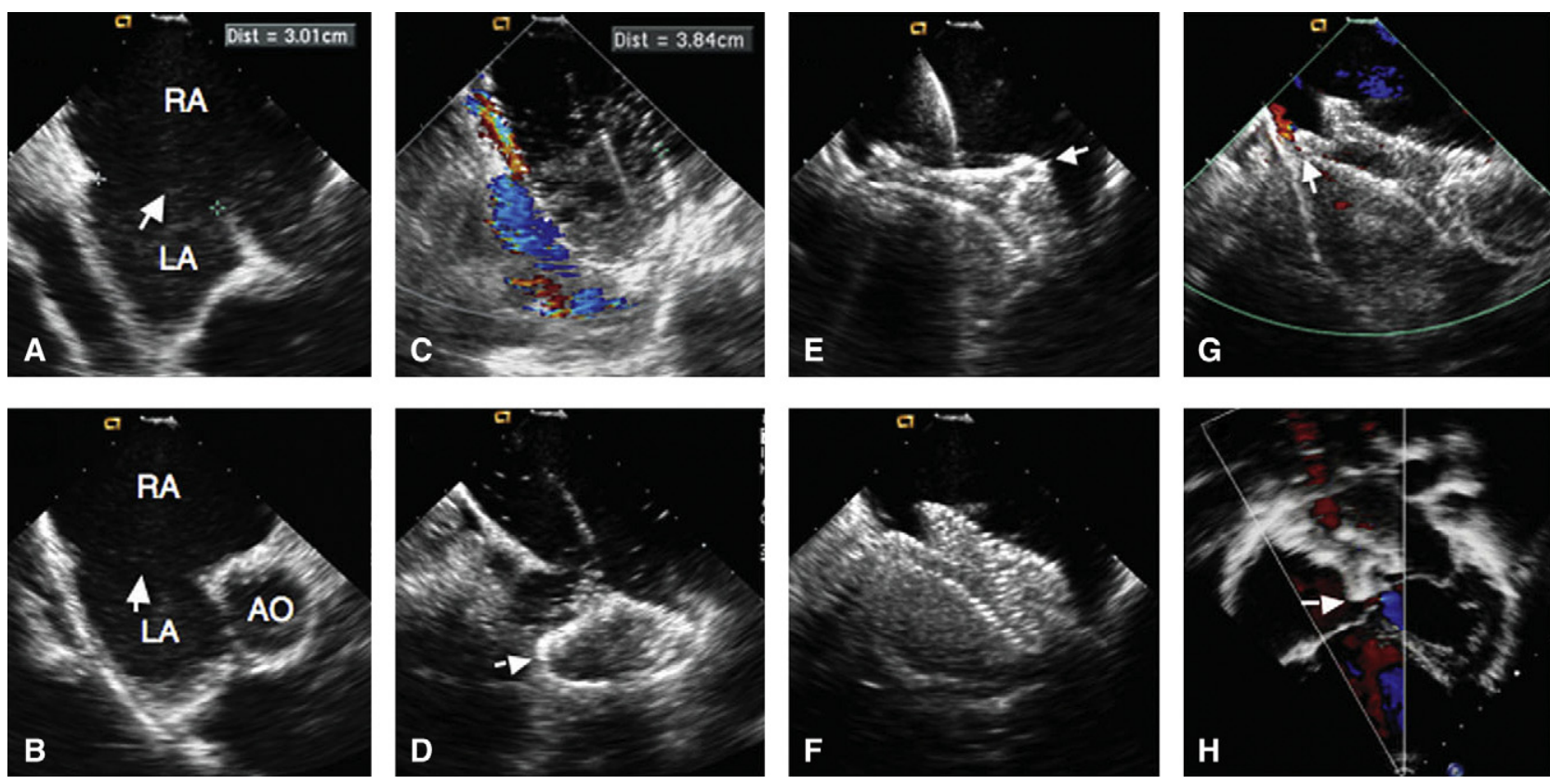

FIGURE 1. A, Intracardiac echocardiography showing about a 30-mm atrial septal defect with a small posteroinferior rim. B, Short-axis view showing a deficient posterior rim. C, Balloon sizing: the stop-flow balloon diameter is $38 \mathrm{~mm}$. D, Left device disc deployed in the left atrium. E, Right device disc deployed in the right atrium. F, Long-axis view (intracardiac echocardiography) of the interatrial septum after release of the device demonstrating good device position. G, Short-axis view (intracardiac echocardiography) of the interatrial septum showing a tiny posterior residual atrial shunt. H, Follow-up transthoracic echocardiogram in 24-hour apical 4-chamber view demonstrating the right atrial disc of the device adjacent to the tricuspid valve septal leaflet. $R A$, Right atrium; $L A$, left atrium; $A O$, aorta. 


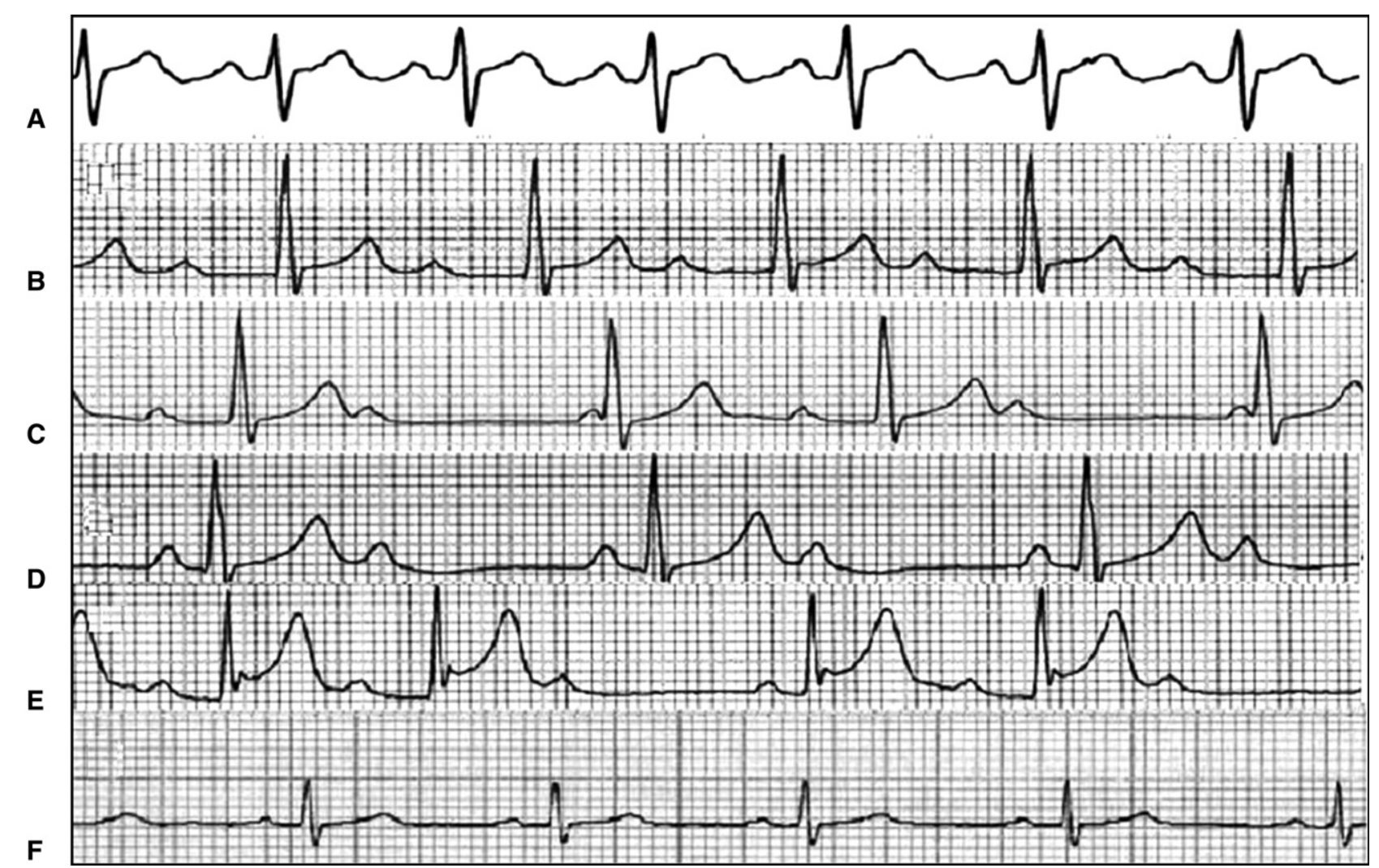

FIGURE 2. Electrocardiogram: A, Normal during the procedure. B, First-degree AV block 12 hours after the procedure. C, Second-degree AV block 36 hours after the procedure. D, AV block (2:1) a few hours after initiating steroid treatment. E, Immediate postoperative Wenckebach second-degree AV block. $\mathrm{F}, \mathrm{AV}$ conduction completely recovered on the ninth postoperative day. $A V$, Atrioventricular.

The patient returned to the hospital after 36 hours with chest pain, shortness of breath, and fatigue. An electrocardiogram revealed complete AV block (Figure 2, $C$ ). After readmission, he was started on a regimen of high-dose aspirin (90 mg/kg/d divided in 3 doses) and steroids ( $40 \mathrm{mg}$ twice daily). After 3 days of medical management he continued to alternate between second-degree 2:1 AV block (Figure 2, $D$ ) and intermittent episodes of symptomatic complete heart block with an escape ventricular rate of 35 beats $/ \mathrm{min}$. An isoproterenol infusion was begun.

Transthoracic echocardiography showed no change in residual shunt, but the device disc was noted to be close to the tricuspid valve with high likelihood of $\mathrm{AV}$ node pressure disturbance. The decision was made to surgically explant the ASO.

In the operating room the device was found to be well positioned. However, owing to a deficient inferior rim of the defect, the ASO was impinging against the AV node.

The device was subsequently removed and the defect was closed with autologous fresh pericardium. Temporary pacemaker leads were then placed and the patient was transferred to the intensive care unit.

By the fourth postoperative day, the patient's rhythm had recovered to second-degree heart block Mobitz type 1. On the ninth postoperative day, the PR interval normalized with 1:1 AV conduction (Figure 2, $E$ and $F$ ) that was documented with 24-hour ambulatory electrocardiographic monitoring. The patient was discharged home and had an uneventful postoperative course with complete resolution of conduction disturbance.

\section{DISCUSSION}

Complete AV block is a rare complication after the ASD device closure. When it develops, it does so in the first few days after the device placement and tends to resolve spontaneously. ${ }^{2}$

Reportedly, variable degrees of heart block after ASO insertion account for $1.6 \%$ of cases, including complete heart block. ${ }^{2}$ Authors have suggested that the size of the device, device/patient height ratio, and the pulmonary/systemic flow ratio are strong determinants of the development of heart block after ASO placement. ${ }^{2}$

There are also reported cases of resolution of complete AV block after device replacement with a smaller device. ${ }^{1}$

High doses of steroids and aspirin have empirically been used to treat these patients. Effectiveness is contingent on device size, the anatomic configuration of the ASD's inferomedial rim, and proximity of the AV node to the inserted 
device. The goal is to alleviate perinodal tissue edema and inflammatory response from the device's compression and stretching effect on the AV node. Such therapy has been applied with variable degrees of success after ASO for atrial or ventricular septal defects. ${ }^{5}$

Our case indicates that persistence of second- or thirddegree heart block for more than 72 hours predicts poor outcome. Time is of the essence in this decision-making to avoid ischemia and fibrosis resulting in permanent injury of the AV node. Leaving the device in place and inserting a permanent pacemaker has also been suggested as an option for progressive heart block. ${ }^{4}$ This would certainly avoid the complications of surgery. However, given the safety and efficacy of surgical closure of ASD and the morbidity associated with pacemaker placement, such as equipment malfunction, certain sports restrictions, infection, and requirement of life-long battery changes, prompt surgical explantation of the ASO and ASD closure is warranted early after this complication occurs and if medical therapy fails to provide complete resolution after the first 72 hours.

\section{References}

1. Chessa M, Carminati M, Butera G, Bini RM, Drago M, Rosti L, et al. Early and late complications associated with transcatheter occlusion of secundum atrial septal defect. J Am Coll Cardiol. 2002;39:1061-5.

2. Suda K, Raboisson MJ, Piette E, Dahdah NS, Miro J. Reversible atrioventricular block associated with closure of atrial septal defects using the Amplatzer device. J Am Coll Cardiol. 2004;43:1677-82.

3. Delaney JW, Li JS, Rhodes JF. Major complications associated with transcatheter atrial septal occluder implantation: a review of the medical literature and the manufacturer and user facility device experience (MAUDE) database. Congenit Heart Dis. 2007;2:256-64

4. Nehgme RA, Huddleston AR, Cheatham JP. Progression to late complete atrioventricular block following Amplatzer device closure of atrial septal defect in a child. Pediatr Cardiol. 2009;30:367-70.

5. Yip WC, Zimmerman F, Hijazi ZM. Heart block and empirical therapy after transcatheter closure of perimembranous ventricular septal defect. Catheter Cardiovasc Interv. 2005;66:436-41.

\title{
Eagle-shaped patch to restore mitral-aortic continuity
}

\author{
Samer Kassem, MD, ${ }^{a}$ Francesco Alamanni, MD, ${ }^{\mathrm{a}}$ and Ghassan A. Moasis, MD, ${ }^{\mathrm{b}}$ Milan, Italy, and \\ Damascus, Syria
}

The reconstruction of aortic-mitral continuity is an uncommon procedure occurring in around $1 \%$ of patients undergoing aortic valve replacement, and it is needed more frequently in case of native or prosthetic valve endocarditis (PVE). ${ }^{1,2} \mathrm{In}$ case of PVE, especially with paravalvular abscess, the infected tissue must be removed thoroughly, even if large defects are created, because leaving infected tissue in situ always carries a high risk of recurrent endocarditis.,

We describe a simple technique for the reconstruction of the mitral-aortic continuity with an eagle-shaped patch that avoids tension on the mitral valve or on healthy nearby tissues.

\section{SURGICAL TECHNIQUE}

Before cardiopulmonary bypass is established, transesophageal echocardiography (TEE) is performed to define the

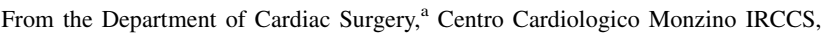
University of Milan, Milan, Italy; and the Department of Cardiac Surgery, ${ }^{\mathrm{b}}$ Assad University Hospital, University of Damascus, Damascus, Syria.

Disclosures: Authors have nothing to disclose with regard to commercial support. Received for publication Aug 10, 2010; accepted for publication Aug 23, 2010; available ahead of print Oct 8, 2010.

Address for reprints: Samer Kassem, MD, Centro Cardiologico Monzino IRCCS, Via

Parea, 4, 20138, Milano, Italy (E-mail: samer.kassem@ccfm.it).

J Thorac Cardiovasc Surg 2011;141:1321-3

$0022-5223 / \$ 36.00$

Copyright (c) 2011 by The American Association for Thoracic Surgery

doi:10.1016/j.jtcvs.2010.08.041
}

anatomic details of the aortic root. Aortic-atrial cannulation for extracorporeal circulation, antegrade and retrograde cold blood cardioplegia, carbon dioxide insufflation of the operative field, and moderate hypothermia $\left(32^{\circ} \mathrm{C}\right)$ are routinely used. The aortic valve is approached through a longitudinal aortotomy, which can be extended into the noncoronary sinus, into the intervalvular fibrous body, and into the anterior mitral leaflet. Once the aortic-mitral continuity needs to be reconstructed, because of the need to remove infected tissue or because of aortic root enlargement, a bovine pericardial patch is used. This patch $(60 \times 30 \mathrm{~mm})$ is prepared by folding it into 3 equal folds at its central part, the height of the folds being about $0.5 \mathrm{~cm}$; the 3 folds are fixed by 2 or 3 interrupted simple sutures of 4-0 polypropylene. At the end, the patch looks like an eagle with 2 wings and a central body (Figure 1, $A$ ).

The 2 sides of the body of the eagle patch are sutured to the lateral and medial fibrous trigones with 2 single stitches of 3-0 polypropylene. Then, the lower wing of the patch is secured without tension to the anterior mitral leaflet with a 5-0 polypropylene locked running suture, whereas the upper wing is sutured to the healthy aortic wall using 4-0 polypropylene running suture (Figure 1, B). Once the body and the wings of the patch are sutured, the body of the eagle patch completes and re-establishes the aortic annulus, which now will be able to accommodate a prosthesis without tension (Figure 2). This is important both on the lower 